\title{
Longitudinal effects of emotion awareness and regulation on mental health symptoms in adolescents with and without hearing loss
}

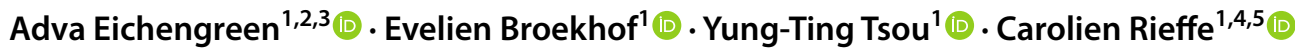

Received: 9 May 2021 / Accepted: 24 October 2021 / Published online: 22 February 2022

(c) The Author(s) 2022

\begin{abstract}
Emotion awareness (EA) and regulation (ER) are each known to associate with mental health symptoms, yet there is a paucity of longitudinal studies examining them jointly during adolescence. Furthermore, little is known about these skills and their relations in deaf and hard-of-hearing (DHH) adolescents, who are at risk for reduced emotion socialization and for more mental health symptoms. This longitudinal study examined the development and unique contributions of EA (emotion differentiation, emotion communication and bodily unawareness) and ER (approach, avoidance and worry/rumination) to internalizing and externalizing symptoms in adolescents with and without hearing loss. Using self- and parent's reports, we assessed 307 adolescents (age 9-15) three times over 18-month period. We found stability over time in development of EA and avoidance ER, increase in approach ER and decrease in worry/rumination. High levels and increases over time in two aspects of EA, emotion differentiation and communication, and in approach and avoidance ER were related to decreases in depressive symptoms. An increase in approach ER was also related to a decrease in anxiety symptoms. Yet, low levels or decreases in worry/rumination were related to decreased levels of depressive, anxiety and externalizing symptoms. Hearing loss did not moderate any of the variables or relations tested. Preliminary tests suggested heterogeneity within the DHH group according to educational placement, language abilities and parental education level. Overall, findings pointed at unique contributions of EA and ER to mental health development, suggesting that DHH adolescents, especially in mainstream schools, do not differ from their hearing peers in their emotion awareness and regulation.
\end{abstract}

Keywords Longitudinal study $\cdot$ Emotion awareness $\cdot$ Emotion regulation $\cdot$ Internalizing and externalizing symptoms $\cdot$ Deaf and hard of hearing

\section{Introduction}

The contribution of emotion awareness (EA) and emotion regulation (ER) to the prevention or generation of psychopathology has long been studied, both in research and in clinical practice [1]. Identifying one's own emotions,

Adva Eichengreen

a.eichengrun@fsw.leidenuniv.nl

Evelien Broekhof

e.broekhof@ fsw.leidenuniv.nl

Yung-Ting Tsou

y.tsou@fsw.leidenuniv.nl

Carolien Rieffe

CRieffe@FSW.leidenuniv.nl

1 Department of Developmental and Educational Psychology, Institute of Psychology, Leiden University, Leiden,

The Netherlands relating them to the triggering situation, and selecting and implementing adaptive regulatory strategies, enable individuals to resolve emotion-evoking situations or to cope with negative emotions in a way that prevents the generation of psychopathological symptoms [1,2]. While most research has been cross-sectional and studied EA

2 Center for Disability Studies, The Paul Baerwald School of Social Work and Social Welfare, The Hebrew University of Jerusalem, Jerusalem, Israel

3 The E. Richard Feinberg Department of Child and Adolescent Psychiatry, Schneider Children's Medical Center, Petah Tikva, Israel

4 Department of Human Media Interaction, Faculty of Electrical Engineering, Mathematics and Computer Science, University of Twente, Enschede, The Netherlands

5 Department of Psychology and Human Development, Institute of Education, University College London, London, UK 
and ER separately from each other, this study applied a longitudinal design to examine the unique contributions of EA and ER to internalizing and externalizing symptoms together. Further, while EA and ER skills are known to be acquired through social learning [3], very little is known about these processes in children and adolescents who have less access to their social environment. Such are deaf and hard-of-hearing (DHH), who are at risk for reduced emotion socialization [e.g., 4] and mental health development [e.g., reviews at 5, 6]. This study is the first to examine the longitudinal effects of EA and ER on mental health development in adolescents with hearing loss, compared to hearing peers.

Awareness of one's own emotions is considered a prerequisite for adaptive regulation [7]. This core feature in our emotional development is defined as an attentional process that enables individuals to identify emotion experiences, differentiate between emotions and locate their antecedents $[2,7,8]$. The ability to identify the cause of the emotions requires directing one's focus from internal bodily arousal to the external environment. It has been shown that a greater ability to identify and differentiate between emotions is related to relative unawareness of bodily sensations during the emotion experience [9]. Besides attentional aspects, EA includes attitudinal aspects, such as the extent to which one tends to, or thinks that one should, communicate emotions to other people $[9,10]$.

EA skills are particularly important during the transition to adolescence, a period characterized by new stressors and a greater vulnerability to mental health symptoms. During this period intense physiological, cognitive, and emotional changes emerge, all of which may lead to increased social and emotional difficulties [11, 12]. At the same time, development in meta-cognitive skills allows adolescents to develop more complex and self-reliant emotion skills [13, 14]. Cross-sectional studies in adolescents have clearly indicated that EA skills, including emotion differentiation, emotion communication, and bodily unawareness, are negatively associated with internalizing symptoms such as depression and anxiety [8-10, 15-19]. Longitudinal studies have shown that emotion differentiation predicted less depressive symptoms over time $[2,8$, $16,20]$. The link between EA and externalizing problems has received much less attention, yet there is cross-sectional evidence of a negative association between emotion differentiation and externalizing symptoms such as conduct problems in adolescents $[19,21]$.

Besides awareness to one's emotions, being able to regulate them is crucial for mental health and includes inducing a change in the generation of one's emotion, the experience of that emotion, or the way the person reacts to and acts on the emotion experience [1]. A variety of regulation strategies have been studied in relation to mental health symptoms in children and adolescents [e.g., review at 13]. One central adaptive category of strategies is approaching the stressor with the aim of modifying it, for instance by actively thinking about how to solve it. Approach strategies are negatively associated with internalizing symptoms such as depression and anxiety [13, 22, 23], and with externalizing symptoms such as aggression and conduct disorder [13]. In addition, cognitive avoidance from the stressor can also be used to regulate internal stress, such as minimizing the importance of the stressor or distracting oneself to a positive cognition/ activity. Avoidance strategies were found to negatively relate to depression in children and adolescents [24] and are effective especially when the stressor is conceived as uncontrollable [25], such as in the experiences of ethnic minority adolescents [25], or adolescents with autism [26]. However, longitudinal evidence of the effectiveness of these adaptive regulation strategies is lacking, with only few studies showing no effect of approach strategies on mental health over time $[13,23]$.

In contrast, rumination has been clearly identified as a maladaptive internalizing regulation strategy, and was conceptualized as a transdiagnostic factor explaining multiple forms of psychopathology [review at 27]. Concurrent and prospective studies in adolescents have shown that the tendency to dwell on the problem by repetitively worrying about it or thinking about its negative meanings is associated with depression and anxiety and predicts them over time $[8$, 27]. Recently, studies in early adolescents have shown that worry/rumination also underlies externalizing symptoms in boys, such as aggressive or disruptive behavior and their comorbidity with internalizing symptoms [28, 29]. Rumination over a provocative trigger may underlie a transition between a depressed or anxious mental state to an aggressive behavior. In turn, provocative or aggressive behaviors can lead to negative social or academic consequences, which by themselves can increase engagement in rumination [28].

Alongside the significant body of research on EA and ER skills in adolescents, only few studies have examined them in tandem, despite the strong association between them [30]. Among the studies which tested the contributions of both emotion awareness and regulation to mental health development composites scores were used, which either unified EA with ER [31, 32], or measured overall levels of EA and ER with no distinction between specific EA/ER skills [20, 33]. Therefore, more research is needed on the contribution of EA and ER to mental health while controlling for the effect of each other, and while disentangling to specific awareness and regulation strategies.

Moreover, there is lack of studies examining the development of EA and ER and their contributions to mental health in adolescents who are at risk for less exposure to interactions within their family and social environments. 
Identifying and labeling one's emotion experiences and developing strategies to regulate them depend to a large extent on linguistic, social, and cultural learning [3, 7]. Both parents and peers play a crucial role in these processes throughout childhood and adolescence. Emotion socialization by parents, peers and other social agents occurs directly, by responding to or guiding the child's emotion expressions, or indirectly by modeling attitudes and skills, which the child observes or overhears [3, 12]. Very little is known about the development of EA and ER in children and adolescents with compromised access to surrounding social interactions. Such are DHH children, who are often born to hearing parents and are raised in auditory-verbal environments in which their access to communication is limited [4]. Difficulties to follow social interactions may make it harder for DHH children and adolescents to infer about the socio-emotional meanings of interactions and learn from them. Overprotectiveness of parents and educators and a reduced discourse on mental states may also result in insufficient socio-emotional coaching of DHH children and adolescents [34, 35].

Importantly, DHH children and adolescents display higher rates of mental health problems compared to hearing peers, in respect to both internalizing and externalizing symptoms [35-38 and reviews at 5, 39]. A recent study in preschoolers showed that even though DHH and hearing groups did not differ on average scores, the DHH group presented a greater variance in rates of psychosocial symptoms [40]. These findings call for further understanding of underlying factors explaining variance in mental health development in DHH children and adolescents. So far, studies have focused on factors such as language, speech, and communication skills $[5,6,38-41]$ or the presence of additional disabilities such as intellectual disabilities $[5,6,39$, 40]. Much less is known about the role of EA and ER in the development of mental health in DHH children and adolescents, although these skills are affected by social learning and language acquisition [5].

To date, limited studies have examined EA and ER in DHH children and adolescents, and all these studies were cross-sectional. Studies on EA [42, 43] indicated that DHH adolescents showed similar abilities as hearing peers for emotion differentiation in simple contexts, but a lower ability to differentiate emotions when situations involved multiple emotions. As to emotion regulation, preschoolers with cochlear implants (CI) [44, 45], and deaf adolescents [42, $46,47]$ were found to express negative emotions more intensively and bluntly compared to hearing peers. They also used problem-focus approach strategies less often [46]. Alternatively, compared to hearing peers, use of approach strategies was experienced by DHH adolescents as less effective in decreasing negative emotion arousal in themselves and in their partners [42]; presumably due to blunt emotion expression and less attention to the partners' perspectives [47]. In addition, compared to hearing peers, DHH children and adolescents made less use of avoidant self-distraction strategies to calm down and were less successful in thinking about ways to recover and be happy again in hypothetical scenarios [42, 44]. Wiefferink and colleagues [44] also suggested that, compared to hearing peers, young DHH kids may benefit more from self-distraction regulation strategies, as the negative relation between self-distraction and externalizing behavior problems was stronger for this group.

\section{The present study}

The goal of this study was twofold. First, we explored the unique longitudinal contributions of EA and ER to internalizing and externalizing symptoms when examined simultaneously. Second, we examined whether there were differences between adolescents with and without hearing loss in baseline levels and in developmental trajectories of EA and ER and in the longitudinal contributions of EA and ER to mental health symptoms. Questionnaires were administered to 9-15-year-olds with and without hearing loss and their parents on three occasions, with a 9-month interval in between. Emotion awareness was investigated through differentiation of one's own emotions, bodily unawareness, and emotion communication. Emotion regulation was investigated through adaptive regulation strategies (approach, avoidance) and maladaptive worry/rumination. Internalizing problems were examined through depressive and anxiety symptoms, and externalizing problems were examined through symptoms of attention deficit hyperactivity, oppositional defiant, and conduct disorders.

Based on cross-sectional studies [44, 46], we expected the DHH group to present lower baseline levels of EA and ER, compared to the hearing group. Next, we examined in both groups the developmental trajectories of EA and ER. Previous cross-sectional research, which compared between different age groups, has shown mixed findings regarding age-related development of EA [8, 12, 19] and ER [14, 48] skills. Due to the limited longitudinal research in this field [13], this part of the investigation was exploratory. At the third step, we tested the contribution of EA and ER to the development of internalizing and externalizing symptoms. Based on longitudinal data from hearing adolescents [e.g., $2,27]$, we expected in both groups to find negative contributions of baseline and change levels of EA and adaptive ER, and a positive contribution of baseline and change levels of worrying/rumination, to the prediction of internalizing and externalizing symptoms. We also expected the negative relation between approach strategies and mental health symptoms to be weaker in the DHH group, based on a previous cross-sectional research which showed that approach strategies and negative emotion arousal were less strongly 
related in DHH adolescents compared to hearing peers [42]. As for other associations between ER strategies and mental health, no specific hypotheses were made on differences in association magnitude due to lack of empirical studies including DHH adolescents, although a stronger negative relation between avoidant ER and externalizing symptoms was found for a sample with younger DHH children [44]. Finally, as it has been suggested that DHH adolescents in special education present more mental health and psychological difficulties compared to DHH peers in mainstream education [49], we conducted preliminary anlayses to compare between these subgroups in levels of EA, ER and mental health symptoms.

\section{Method}

\section{Participants}

This study was part of a larger project on socio-emotional functioning in children with and without communication difficulties [e.g., 29, 50]. The DHH and hearing samples in this study are the same as in a previous study on bullying and aggression [51]. Part of the cross-sectional data assessed at Time 1 has been previously published [52-54]. A total of 307 adolescents between 9 and 15 years $(M=11.71$, $\mathrm{SD}=1.45$ at Time 1) participated in this study, out of which 80 were DHH and 227 hearing. DHH participants were recruited through hospitals' Otorhinolaryngology departments, speech and hearing centers, special schools for the deaf, and publications at magazines and websites of organizations giving services to DHH youth and their caregivers. Inclusion criteria for the DHH participants was having a prelingual hearing loss of at least $40 \mathrm{~dB}$ in the better ear. Hearing participants were recruited nationwide through mainstream schools. The groups did not differ in age (Time 1: $t(305)=-1.47, p=0.142)$; gender distribution $\left(\chi^{2}(307)=\right.$ $-0.37, p=0.539)$, IQ score $(t(274)=1.13, p=0.259)$, language ability $(t(252)=0.09, p=0.932)$, and parental education level $(t(231)=-0.45, p=0.656)$. Participants' characteristics are presented in Table 1.

\section{Materials}

\section{Personal characteristics}

$I Q$ was assessed using the two nonverbal subtests of the WISC-III (WISC-III ${ }^{\mathrm{NL}}$ ), Block Design and Picture Arrangement $[55,56]$. For the Block Design subtest children had to copy geometric designs with plastic cubes. For the Picture Arrangement subtest, children had to arrange cartoons in a specific sequence in order to make logical stories. The
Table 1 Demographic characteristics of participants

\begin{tabular}{|c|c|c|}
\hline & DHH & Hearing \\
\hline No. of participants & 80 & 227 \\
\hline \multicolumn{3}{|l|}{ Age in years at $\mathrm{T} 1$} \\
\hline Mean $(S D)$ & $11.91(1.62)$ & $11.63(1.38)$ \\
\hline Range & $9.17-15.75$ & $9.08-14.75$ \\
\hline \multicolumn{3}{|l|}{ Gender- $n(\%)$} \\
\hline Male & $37(46.3)$ & $96(42.3)$ \\
\hline Female & $43(53.8)$ & $131(57.7)$ \\
\hline IQ score $(S D)$ & $10.19(2.67)$ & $10.61(2.48)$ \\
\hline Language score $(S D)$ & $10.29(3.30)$ & $10.32(2.30)$ \\
\hline Parental education level $\dagger(S D)$ & $3.21(.72)$ & $3.17(.66)$ \\
\hline \multicolumn{3}{|l|}{ Type of education $-n(\%)$} \\
\hline Regular education & $48(60.0)$ & $227(100.0)$ \\
\hline Special education & $32(40.0)$ & 0 \\
\hline \multicolumn{3}{|l|}{ Communication mode- $n(\%)$} \\
\hline $\begin{array}{l}\text { Dutch Sign Language /Sign Sup- } \\
\text { ported Dutch }\end{array}$ & $28(35.0)$ & \\
\hline Spoken Language only & $52(65.0)$ & \\
\hline \multicolumn{3}{|l|}{ Type of amplification- $n(\%)$} \\
\hline Hearing aid & $53(66.3)$ & \\
\hline Cochlear implant (CI) & $27(33.3)$ & \\
\hline \multicolumn{3}{|l|}{ Hearing loss in best ear- $n(\%)$} \\
\hline $40-60 \mathrm{~dB}$ & $20(25.0)$ & \\
\hline $61-90 \mathrm{~dB}$ & $18(22.5)$ & \\
\hline$>90 \mathrm{~dB}$ & $36(45.0)$ & \\
\hline Unknown & $6(7.5)$ & \\
\hline
\end{tabular}

$D H H$ Deaf or heard of hearing, SD Standard Deviation, $T$ Time

†The highest level of education of each parent was categorized on a scale ranging from one to four. Parental education level was calculated by averaging these two scores

obtained scores were converted into age-corrected norm scores, and a mean IQ score was calculated based on the two norm scores $(M=10)$.

Language ability was assessed using two subtests of the Clinical Evaluation of Language Fundamentals-Fourth edition [CELF; 57] In the first subtest on understanding spoken paragraphs, participants were presented with spoken information and asked to answer questions about the content. The second subtest, semantic relations, measured the ability to understand sentences involving comparisons, location, serial order, and time relations. Participants listened to a sentence and selected two correct answers from four presented alternatives. The scores were converted into age-corrected norm scores $(M=10)$, and a mean language score was calculated based on the two norm scores (Table 1). 


\section{Predictors}

\section{Emotion awareness}

To measure EA we used the Dutch version of the Emotion Awareness Questionnaire Revised [EAQ-R; 9]. The EAQ is a self-report questionnaire whose original form consists of 30 items representing six subscales that measure EA. For the purpose of this study, we used three scales, consisted of twenty-five items in total: The first scale, Differentiating Emotions, referring to the ability to differentiate between emotions and locate their antecedents, consists of seven items (e.g., "When I am upset, I don't know if I feel angry or sad", reverse scored). The second scale, Bodily Unawareness, referring to lack of attention to physiological aspects of the emotion experience, consists of five items (e.g., "When I am sad, my body feels weak", reversed scored). The third scale, Communicating Emotions (previously the scales Verbal Sharing and Not Hiding Emotions), assessing the tendency to share and explain one's emotions to other people in a verbal way, consists of eight items (e.g., "I find it difficult to tell others how I feel", reversed scored). Following the original scale's format participants were asked to rate their responses to EAQ-R items on a 3 -point scale ( $1=$ not true, $2=$ sometimes true, $3=$ often true). Cronbach alpha reliability of the EAQ-R scales has been reported to range between acceptable to good [19]. In this study internal consistencies of the three scales were adequate across the time points $(0.65 \leq \alpha \leq 0.81)$.

\section{Emotion regulation}

To measure adaptive ER, the Dutch version of the Coping Scale [58] was administered to indicate which ER strategies would be used in hypothetical problematic peer scenarios. The Coping Scale [23] consists of six ER strategies, which fall into three subscales. We used the Approach Scale (Problem Solving and Seeking Social Support subscales) and Avoidant Scale (Distraction and Trivialising subscales), each consisted of 12 items. Approach strategies involved approaching the stressor to calm down (e.g., "I try to think of different ways to solve the problem" and "I ask someone in my family for advice"), whereas avoidant strategies involved creating distance from the emotion-evoking situation to calm down (e.g., "I do something else to help me forget about it" and "I tell myself it doesn't matter"). Participants were first instructed to imagine a problematic scenario with a peer. Then they answered how often they would use a certain strategy by rating each statement on a 3-point scale $(1=$ almost never, $2=$ sometimes, $3=$ often $)$. The scales were reported to have good reliability [58]. The internal consistencies of approach and avoidant scales in this study were good across the three measurements $(0.81 \leq \alpha \leq 0.87)$.
To measure maladaptive ER, we used the Worry/rumination questionnaire for children [29, 59]. This 10-item selfreport assesses the tendency to dwell on the problem instead of solving it or coping adaptively with its emotional impact. Example items are "When I have a problem, I can't stop thinking about it" and "When I make a mistake, I am worried about what might happen". Items were rated on a 3-point scale ranging from $1=$ not true to $3=$ often true. Reliability was reported to be good [29]. The internal consistencies in this study were good across the three time points $(0.84 \leq \alpha \leq 0.86)$.

\section{Outcome measures}

\section{Depressive symptoms}

Depressive symptoms were measured with the Dutch version of the Children's Depression Inventory [CDI; 60, Dutch version by 61]. The CDI is a 27-item self-report measure assessing symptoms associated with depression. Example items are "I am sad" and "I do not like myself". Items were rated on a 3 -point scale ( $1=$ never/hardly true, $2=a$ bit true, 3 =very true). The item pertaining to suicidal ideation was removed from the measure. In the analysis we used the mean score of the remaining 26 items. The reliability of the scale was reported as good [60]. In this study the internal consistencies across the three time points were adequate $(0.73 \leq \alpha \leq 0.75)$.

\section{Anxiety symptoms}

The Child Symptom Inventory [CSI; 62, Dutch version: 63] is a behavior rating-scale to assess childhood disorders based on DSM-IV criteria. The parent checklist was used to assess problems related to generalized anxiety. Parents rated children's generalized anxiety symptoms in the last six months on seven items (e.g., "Is very tense or unable to relax". Ratings were made on a 4-point scale ranging from $1=$ never to $4=$ very often. Internal consistency ranged from acceptable to good [62]. In this study the internal consistencies across the three time points were good $(0.77 \leq \alpha \leq 0.80)$.

\section{Externalizing symptoms}

The CSI was also used to assess problems related to attention deficit hyperactivity disorder (ADHD), oppositional defiant disorder (ODD) and conduct disorder (CD). Seventeen items assessed the symptoms of ADHD (e.g., "Is quickly distracted"), eight items assessed symptoms of ODD (e.g., "Does things to deliberately annoy others") and 15 items assessed symptoms of CD (e.g., "Has deliberately started fires"). Parents were asked to rate each symptom on 
Table 2 Psychometric properties and mean scores (standard deviations) of study variables at each time point

\begin{tabular}{|c|c|c|c|c|c|c|}
\hline \multirow[t]{2}{*}{ Parameters } & \multirow[t]{2}{*}{$N$ items } & \multirow[t]{2}{*}{ Scale } & \multirow[t]{2}{*}{ Cronbach's $\alpha$} & \multicolumn{2}{|c|}{ Mean scores (SD) } & \multirow[t]{2}{*}{$t$-value $\mathrm{e}^{\mathrm{a}}$} \\
\hline & & & & $\mathrm{DHH}$ & Hearing & \\
\hline \multicolumn{7}{|l|}{ Time 1} \\
\hline Differentiating emotions & 7 & $1-3$ & 0.78 & $2.30(0.45)$ & $2.39(0.43)$ & 1.47 \\
\hline Bodily unawareness & 5 & $1-3$ & 0.65 & $1.96(0.44)$ & $1.84(0.47)$ & $-2.01^{*}$ \\
\hline Emotion communication & 8 & $1-3$ & 0.76 & $2.11(0.37)$ & $2.05(0.45)$ & -1.06 \\
\hline Approach strategies & 12 & $1-3$ & 0.81 & $2.10(0.38)$ & $2.13(0.41)$ & 0.67 \\
\hline Avoidant strategies & 12 & $1-3$ & 0.82 & $1.86(0.40)$ & $1.89(0.39)$ & 0.46 \\
\hline Worry/rumination & 10 & $1-3$ & 0.86 & $1.92(0.48)$ & $1.90(0.46)$ & -0.40 \\
\hline Depressive symptoms & 26 & $1-3$ & 0.75 & $1.38(0.21)$ & $1.32(0.19)$ & $-2.42^{*}$ \\
\hline Anxiety symptoms & 7 & $1-4$ & 0.80 & $1.51(0.46)$ & $1.41(0.36)$ & -1.47 \\
\hline Externalizing symptoms & 40 & $1-4$ & 0.90 & $1.40(0.20)$ & $1.33(0.23)$ & $-2.13^{*}$ \\
\hline \multicolumn{7}{|l|}{ Time 2} \\
\hline Differentiating emotions & 7 & $1-3$ & 0.74 & $2.38(0.42)$ & $2.39(0.39)$ & 0.07 \\
\hline Bodily unawareness & 5 & $1-3$ & 0.70 & $2.04(0.44)$ & $1.86(0.51)$ & $-2.74 * *$ \\
\hline Emotion communication & 8 & $1-3$ & 0.74 & $2.09(0.39)$ & $2.04(0.40)$ & -1.08 \\
\hline Approach strategies & 12 & $1-3$ & 0.87 & $2.16(0.45)$ & $2.24(0.43)$ & 1.40 \\
\hline Avoidant strategies & 12 & $1-3$ & 0.86 & $1.95(0.44)$ & $1.94(0.41)$ & -0.13 \\
\hline Worry/rumination & 10 & $1-3$ & 0.85 & $1.77(0.45)$ & $1.86(0.47)$ & 1.58 \\
\hline Depressive symptoms & 26 & $1-3$ & 0.73 & $1.36(0.19)$ & $1.32(0.18)$ & -1.28 \\
\hline Anxiety symptoms & 7 & $1-4$ & 0.77 & $1.44(0.38)$ & $1.43(0.37)$ & -0.14 \\
\hline Externalizing symptoms & 40 & $1-4$ & 0.90 & $1.33(0.21)$ & $1.33(0.22)$ & -0.02 \\
\hline \multicolumn{7}{|l|}{ Time 3} \\
\hline Differentiating emotions & 7 & $1-3$ & 0.78 & $2.46(0.46)$ & $2.38(0.39)$ & -1.37 \\
\hline Bodily unawareness & 5 & $1-3$ & 0.76 & $1.96(0.51)$ & $1.83(0.51)$ & -1.75 \\
\hline Emotion communication & 8 & $1-3$ & 0.81 & $2.20(0.40)$ & $2.06(0.44)$ & $-2.16^{*}$ \\
\hline Approach strategies & 12 & $1-3$ & 0.86 & $2.24(0.41)$ & $2.27(0.42)$ & 0.58 \\
\hline Avoidant strategies & 12 & $1-3$ & 0.83 & $2.01(0.35)$ & $1.96(0.39)$ & -0.93 \\
\hline Worry/rumination & 10 & $1-3$ & 0.84 & $1.72(0.43)$ & $1.85(0.44)$ & $1.97 *$ \\
\hline Depressive symptoms & 26 & $1-3$ & 0.74 & $1.32(0.19)$ & $1.28(0.17)$ & -1.68 \\
\hline Anxiety symptoms & 7 & $1-4$ & 0.80 & $1.48(0.39)$ & $1.41(0.40)$ & -1.06 \\
\hline Externalizing symptoms & 40 & $1-4$ & 0.91 & $1.34(0.20)$ & $1.31(0.23)$ & -1.03 \\
\hline
\end{tabular}

DHH Deaf or hard of hearing, $S D$ Standard Deviation

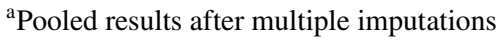

${ }^{*} p<0.05$; ** $p<0.01$

a 4-point scale, ranging from $1=$ never to $4=$ very often . Internal consistency has been reported to be high [29]. The internal consistencies in this study were excellent across the three time points $(0.90 \leq \alpha \leq 0.91)$ (Table 2$)$.

\section{Procedure}

This study was approved by the Ethics Committee of Leiden University. Written parental consent was obtained for all the participants. Parent and self-reports were completed on three measurement occasions, with 9-month intervals. The mean duration of the intervals was 9.38 months $(S D=0.85)$ between Time 1 and Time 2, and 9.93 months $(S D=1.13)$ between Time 2 and Time 3 .
Participants were tested individually in a quiet room at home or at school. All questions were presented on a laptop one by one. For DHH participants, all written questions were accompanied by an optional video translation in sign language. Tests for IQ and language ability were administered at Time 2. Parents were asked to complete questionnaires online or with paper and pencil. With parents' consent, details about the participants' hearing loss were obtained from medical records.

\section{Statistical analyses}

Statistical analyses were performed using SPSS version 25.0 (SPSS Inc., Chicago, IL, USA). Graphs were made in R 
version 3.6.3 (Ggplot2 package). Correlations between study variables are reported in Appendix Table 7. Graphic representations of individual variations in the study variables over time are shown in Appendix Fig. 1. Longitudinal analyses were conducted using linear mixed models (LMMs) with maximum likelihood estimation [64]. Our data had a twolevel structure with time points (level 1) nested within participants (level 2), and LMMs allow this within-participant dependency to be accounted for.

To analyze levels and developmental trajectories of emotion awareness and regulation across time, increasingly more complex LMMs were fitted to the data via a formal modelfitting procedure. We started with an unconditional means model that included only a fixed and random intercept, which was then compared to additional models that tested the grand mean trajectory of age (centered around 9 years, i.e., the age of the youngest child). We examined two age models: linear and quadratic trends. A random-slope effect for age was added to the best age model. Yet, adding the quadratic trend and random effect of age did not improve model fits, so these results are not reported here. The next model included group $(0=$ hearing, $1=\mathrm{DHH})$ and the interaction between age and group, to examine whether levels and developmental trajectories differed between DHH and hearing participants.

To test whether changes in emotion awareness and regulation contributed to changes in mental health symptoms, we first calculated for each predictor variable a baseline score (Time 1) and a change score (i.e., Time 1 - Time 1, Time 2 - Time 1, Time 3 - Time 1). The baseline score was added to the model to examine the contribution to mental health of between-person differences in baseline levels of EA and ER, and the change score was added to examine the contribution of within-person changes in EA and ER. We started with fitting a LMM with control variables (age, gender, language, and group) and predictor variables (baseline and change scores), to assess the unique contribution of each predictor to the development of mental health symptoms. Next, the interactions between each predictor (baseline and change scores) and group were added to the model. Additionally, we, respectively, left out EA variables and ER variables from the model to examine if the results changed when these variables were not controlled for, which was not the case and thus are not reported here. Preferred models had significantly lower Akaike Information Criterion [AIC; 65] and Bayesian Information Criterion [BIC; 66]) values compared to simpler models.

A preliminary analysis was conducted to compare between DHH participants attending mainstream schools $(n=48)$, DHH participants attending special education $(n=32)$, and hearing participants $(n=227)$, using multivariate analysis of variance (MANOVA) with Bonferroni corrections. The dependent variables were the mean levels of the study variables, averaged across all time points. Pearson's correlations were used to examine the association across time points between EA, ER, age, and mental health symptoms. Fisher's $r$ to $\mathrm{Z}$ transformations were used to compare the strength of correlations between the groups.

Three post-hoc analyses were conducted to test whether differences between and within the DHH and hearing groups could be accounted for by socio-demographic (parental education) and developmental (IQ, language competency) variables. Using the DHH sample's median scores as the cut-off points three MANOVA tests with Bonferroni corrections were applied to examine the differences in the mean level of EA, ER, and mental health symptoms (averaged across time points) between DHH participants with high profiles ( $n=41 / 44 / 33$ for parental education/IQ/language scores respectively), DHH with low profiles $(n=39 / 36 / 47)$, hearing with high profiles $(n=90 / 147 / 97)$, and hearing with low profiles $(n=137 / 80 / 130)$.

\section{Missing values and multiple imputations}

In this study, 63 (79\%) DHH and 166 (73\%) hearing participants had data at all time points. Participants with and without missing data points did not differ in age at Time 1, gender distribution, IQ, and parental education level. Yet, participants who dropped out had lower language scores than participants who attended all test sessions, $t(252)=2.56$, $p=0.011$. Little's MCAR test showed that data were not missing completely at random $(p=0.007)$. Yet, the values were missing for known reasons. For example, dropouts and missing IQ and language scores were mainly due to time constraints, and hearing participants were more likely to drop out than DHH participants because DHH participants regularly visited the services where we collected the data. Thus, we assumed that the data were missing at random.

Although LMMs can account for missing follow-up data points of a participant [67], missing values in independent variables at baseline could still result in bias [68]. We thus handled the missing values at Time 1 using multiple imputations [MI; 69]), which estimates missing values based on participant characteristics and relations in the data among the participants [70]. The variables included for the estimation were age, gender, hearing status, IQ, language ability, parental education level, and parent- and self-reports. We performed ten imputations [71], and report the pooled results. An overview of missing data is shown in Appendix Table 8. 


\section{Results}

\section{Developmental trajectories of emotion awareness and regulation}

Table 3 presents the best-fitting models explaining developmental trends of EA and ER. No developmental trends were found for differentiating emotions, bodily unawareness and communicating emotions. Regarding ER, the use of approach strategies increased with age $(b=0.004, p<0.001)$, the use of avoidant strategies did not show a developmental trend, and the use of worry/rumination decreased with age $(b=-0.002, p=0.049)$.

\section{Longitudinal effects of emotion awareness and regulation on mental health}

Table 4 presents the best-fitting models explaining the longitudinal relations of EA and ER with mental health symptoms. Levels of depressive symptoms were not related to age. Higher baseline levels and an increase over time in differentiating emotions (baseline score: $b=-0.10, p<0.001$; change score: $b=-0.06, p=0.002)$, communicating emotions (baseline score: $b=-0.06, p=0.006$; change score: $b=-0.04, p=0.037$ ), approach strategies (baseline score: $b=-0.10, p<0.001$; change score: $b=-0.06, p<0.001)$, and avoidant strategies (baseline score: $b=-0.04, p=0.029$; change score: $b=-0.06, p<0.001)$ contributed to developing fewer depressive symptoms. A lower baseline level and a decrease in worry/rumination over time (baseline score: $b=0.12, p<0.001$; change score: $b=0.08, p<0.001$ ) also contributed to the development of fewer depressive symptoms.
Levels of anxiety symptoms were not related to age. An increase in the use of approach strategies (change scores: $b=-0.08, p=0.040$ ), and a decrease in worry/rumination over time (change scores: $b=0.09, p=0.045$ ) contributed to developing fewer anxiety symptoms.

Levels of externalizing symptoms decreased with age ( $b=-0.001, p=0.018)$. Lower baseline levels of bodily unawareness (baseline score: $b=0.08, p=0.011$ ) and a decrease in worry/rumination over time (change score: $b=0.07, p=0.001$ ) contributed to developing fewer externalizing behaviors.

\section{Differences between and within DHH and hearing participants}

No differences were found between DHH and hearing participants in baseline levels and developmental trends of EA and ER skills (Table 3). The groups also did not differ in levels of anxiety or externalizing symptoms across time, yet DHH participants had higher levels of depression compared to hearing participants $(b=0.04, p=0.007)$ (Table 4). As presented in Table 4, none of the longitudinal models included interactions between group and longitudinal relations, meaning that the $\mathrm{DHH}$ and hearing groups did not differ in the longitudinal relations between EA, ER and mental health symptoms.

Next, the school placement of the participants was examined. Table 5 presents the results of the preliminary MANOVA test, examining group differences between hearing participants, DHH participants studying in mainstream schools, and DHH participants studying in special education, in levels of EA, ER, and mental health symptoms across time points. Findings showed a main effect for group differences $(F(18,592)=3.09, p<0.001$, Wilk's $\Lambda=0.79)$, qualified by

Table 3 Regression weights (standard error) examining group differences and the developmental trajectory of emotion awareness and emotion regulation

\begin{tabular}{|c|c|c|c|c|c|c|}
\hline \multirow[t]{2}{*}{ Parameter } & \multicolumn{3}{|c|}{ Emotion awareness } & \multicolumn{3}{|l|}{ Emotion regulation } \\
\hline & $\begin{array}{l}\text { Differentiating } \\
\text { emotions }\end{array}$ & $\begin{array}{l}\text { Bodily unaware- } \\
\text { ness }\end{array}$ & $\begin{array}{l}\text { Emotion commu- } \\
\text { nication }\end{array}$ & $\begin{array}{l}\text { Approach strate- } \\
\text { gies }\end{array}$ & $\begin{array}{l}\text { Avoidant strate- } \\
\text { gies }\end{array}$ & Worry/rumination \\
\hline \multicolumn{7}{|l|}{ Fixed effects } \\
\hline Intercept & $2.38(0.02)^{* * *}$ & $1.89(0.02)^{* * *}$ & $2.07(00.02)^{* * *}$ & $2.01(0.04)^{* * *}$ & $1.93(0.02)^{* * *}$ & $1.93(0.04) * * *$ \\
\hline Age & - & - & - & $0.004(0.001)^{* * *}$ & - & $-0.002(0.001)^{*}$ \\
\hline Group & - & - & - & - & - & - \\
\hline Age x Group & - & - & - & - & - & - \\
\hline \multicolumn{7}{|l|}{ Random effects } \\
\hline $\begin{array}{l}\text { Variance (Inter- } \\
\text { cept) }\end{array}$ & $0.09(0.01)^{* * *}$ & $0.12(0.01)^{* * *}$ & $0.09(0.01)^{* * *}$ & $0.09(0.01)^{* * *}$ & $0.07(0.01)^{* * *}$ & $0.13(0.01)^{* * *}$ \\
\hline AIC/BIC & $725.34 / 739.43$ & $977.55 / 991.65$ & $754.41 / 768.50$ & $705.45 / 724.24$ & $703.29 / 717.39$ & $774.74 / 793.53$ \\
\hline
\end{tabular}

Group: $0=$ hearing, $1=$ deaf or hard of hearing. AIC Akaike Information Criterion, BIC Bayesian Information Criterion ${ }^{*} p<0.05,{ }^{* *} p<0.01,{ }^{* * *} p<0.001$ 
Table 4 Regression weights (standard error) examining the effect of emotion awareness and emotion regulation on symptoms of depression, anxiety, and externalizing behaviors

\begin{tabular}{|c|c|c|c|c|c|c|}
\hline Parameter & Depressive symptom & & $\begin{array}{l}\text { Anxiety } \\
\text { symptoms }\end{array}$ & & $\begin{array}{l}\text { Externalizing } \\
\text { behaviors }\end{array}$ & \\
\hline \multicolumn{7}{|l|}{ Fixed effects } \\
\hline Intercept & \multicolumn{2}{|l|}{$1.82(0.11)^{* * *}$} & \multicolumn{2}{|l|}{$1.55(0.32)^{* * *}$} & \multicolumn{2}{|l|}{$1.59(0.21)^{* * *}$} \\
\hline Age & \multicolumn{2}{|l|}{$-0.0001(0.0003)$} & \multicolumn{2}{|l|}{$-0.0004(0.001)$} & \multicolumn{2}{|l|}{$-0.001(0.0005)^{*}$} \\
\hline Group & \multicolumn{2}{|l|}{$0.04(0.02)^{* *}$} & \multicolumn{2}{|l|}{$0.05(0.05)$} & \multicolumn{2}{|l|}{$0.04(0.03)$} \\
\hline Gender & \multicolumn{2}{|l|}{$-0.01(0.01)$} & \multicolumn{2}{|l|}{$0.03(0.04)$} & \multicolumn{2}{|l|}{$-0.03(0.02)$} \\
\hline \multirow[t]{2}{*}{ Language } & \multicolumn{2}{|l|}{$-0.01(0.003)^{* *}$} & \multicolumn{2}{|l|}{$0.002(0.01)$} & \multicolumn{2}{|l|}{$-0.01(0.01)^{*}$} \\
\hline & Baseline & Change & Baseline & Change & Baseline & Change \\
\hline \multicolumn{7}{|l|}{ Emotion awareness } \\
\hline Differentiating emotions & $-0.11(0.02)^{* * *}$ & $-0.06(0.02)^{* *}$ & $-0.02(0.06)$ & $-0.060(0.04)$ & $-0.01(0.03)$ & $0.002(0.02)$ \\
\hline Bodily unawareness & $0.02(0.02)$ & $-0.01(0.02)$ & $0.05(0.05)$ & $-0.02(0.04)$ & $0.08(0.03)^{*}$ & $0.04(0.02)$ \\
\hline Emotion communication & $-0.06(0.02)^{* *}$ & $-0.04(0.02)^{*}$ & $-0.004(0.07)$ & $-0.02(0.04)$ & $-0.04(0.03)$ & $-0.03(0.02)$ \\
\hline \multicolumn{7}{|l|}{ Emotion regulation } \\
\hline Approach strategies & $-010(0.02)^{* * *}$ & $-0.06(0.02)^{* * *}$ & $-0.07(0.06)$ & $-0.08(0.04)^{*}$ & $-0.01(0.03)$ & $-0.03(0.02)$ \\
\hline Avoidant strategies & $-0.04(.02)^{*}$ & $-0.06(0.02)^{* * *}$ & $-0.06(0.05)$ & $0.03(0.04)$ & $-0.01(0.03)$ & $0.03(0.02)$ \\
\hline Worry/rumination & $0.12(0.02)^{* * *}$ & $0.08(0.02)^{* * *}$ & $0.08(0.06)$ & $0.09(0.04)^{*}$ & $0.02(0.04)$ & $0.07(0.02)^{* *}$ \\
\hline AIC/BIC & $-824.88 /-735.68$ & & $485.83 / 572.89$ & & $-455.09 /-368.04$ & \\
\hline
\end{tabular}

Group: $0=$ hearing, $1=$ deaf or hard of hearing. Gender: $0=$ boys, $1=$ girls. AIC $=$ Akaike Information Criterion; BIC $=$ Bayesian Information Criterion. Adding group interactions did not improve the models

${ }^{*} p<.05,{ }^{* *} p<.01,{ }^{* * *} p<.001$

effects for approach strategy $(F(2,304)=7.64, p=0.001$, $\left.\eta_{p}{ }^{2}=0.05\right)$, and for depressive symptoms $(F(2,304)=5.90$, $p=0.003, \eta_{p}{ }^{2}=0.04$ ). Post-hoc $t$-tests showed that DHH participants in special schools made less use of approach strategies and scored higher on depressive symptoms compared to the other groups. There were no differences between DHH participants in mainstream schools and the hearing participants. Descriptive statistics and results of correlation tests for the three groups are presented in Appendixes Tables 9, 10,11 . Although some significant differences in correlation sizes were detected, none of the groups was clearly
Table 5 Results of a

multivariate analysis of variance for comparing the mean levels of emotion awareness, emotion regulation, and mental health symptoms between hearing participants, DHH participants in mainstream schools (DHHm), and DHH participants in special education schools (DHHs)

\begin{tabular}{llll}
\hline $\begin{array}{l}\text { Dependent variable } \\
\text { (Mean across time points) }\end{array}$ & $F$-value & $p$-value ${ }^{\mathrm{a}}$ & Pairwise comparisons $^{\mathrm{b}}$ \\
\hline Differentiating emotions & 0.86 & 0.426 & \\
Bodily unawareness & 3.89 & 0.022 & \\
Emotion communication & 1.54 & 0.216 & $\begin{array}{c}\text { DHHs }<\text { DHHm (adjusted } \\
\text { Approach strategies }\end{array}$ \\
& 7.64 & $\mathbf{0 . 0 0 1}$ & $\begin{array}{l}\text { ing (adjusted } p=0.003 \text { ); } \\
\text { DHHm }=\text { Hearing }\end{array}$ \\
Avoidant strategies & & & \\
Worry/rumination & 0.52 & 0.593 & DHHs $>$ DHHm (adjusted \\
Depressive symptoms & 0.23 & 0.795 & $p=0.023$ ); DHHs $>$ Hear- \\
& 5.90 & $\mathbf{0 . 0 0 3}$ & ing (adjusted $p=0.002$ ); \\
& & & DHHm $=$ Hearing \\
Anxiety symptoms & 1.99 & 0.138 & \\
Externalizing behaviors & 1.12 & 0.327 & \\
\hline
\end{tabular}

$D H H-m$ DHH participants attending mainstream schools $(n=48)$, DHH-s DHH participants attending special education $(n=32)$; Hearing: hearing participants (all studying in mainstream schools) $(n=227)$

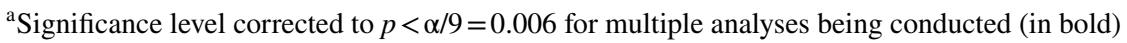

${ }^{\mathrm{b}} p$-values reported here are already adjusted by Bonferroni correction 
differentiated from the other two groups, and, therefore, these correlations are not reported here.

Last, the participants' socio-demographic (parental education) and developmental (IQ, language competency) profiles were examined post-hoc. Within the DHH group, DHH children attending mainstream schools were overrepresented among the high-profile groups $(72 \% / 70 \% / 79 \%$ of DHH groups high in parental education, IQ and language scores, respectively), while DHH children attending special schools comprised the majority of the low profile DHH groups (64\%/53\%/53\%, respectively). Table 6 presents the results of the MANOVA tests, examining group differences in levels of EA, ER, and mental health symptoms across time points. Findings showed a main effect for language scores $(F(27,862.19)=2.64, p<0.001$, Wilk's $\Lambda=0.79)$, qualified by effects for differentiating emotions $(F(27$, $862.19)=6.47, p<0.001, \eta_{p}{ }^{2}=0.06$ ), for depressive symptoms $\left(F(27,862.19)=11.01, p<0.001, \eta_{p}{ }^{2}=0.10\right)$, and for externalizing behaviours $(F(27,862.19)=4.56, p=0.004$, $\left.\eta_{p}{ }^{2}=0.04\right)$. Pairwise comparisons indicated that DHH participants high in language competency presented better ability to differentiate emotions when compared to both DHH or hearing participants with low language competency. Similarly, hearing participants with high language proficiency showed fewer externalizing symptoms when compared to both DHH or hearing participants with low language proficiency. Yet, when depressive symptoms were examined, a unique pattern was observed for the low linguistic-profile DHH group. While all participants with low language scores showed more depressive symptoms when compared to highprofile groups of the same hearing status (DHH-h $<$ DHH-l; Hearing-h $<$ Hearing-1), the low-profile DHH group scored higher on depressive symptoms when compared to all other groups, including low-profile hearing counterparts.

Findings also indicated a main effect for parental education which was very close to the Bonferroni correction cut-off point $(F(27,862.19)=1.67, p=0.018$, Wilk's $\Lambda=0.86$ ), qualified by an effect for depressive symptoms $\left(F(27,862.19)=4.02 p=0.008, \eta_{p}{ }^{2}=0.04\right)$. Pairwise comparison indicated that DHH participants with a low level of parental education scored higher on depressive symptoms when compared to both high-profile and low-profile hearing participants.

\section{Discussion}

This study employed a longitudinal design to examine the development of emotion awareness and regulation skills during adolescence and their unique contributions to the development of mental health symptoms over time in adolescents with and without hearing loss. Importantly, DHH and hearing adolescents did not differ in their baseline levels, developmental trajectories of EA and ER skills, nor in the way or strength EA and ER skills were related to mental health symptoms. Preliminary analyses suggested heterogeneity within the DHH group according to educational placement, language abilities, and parental education level, which may partly explain the differences found in previous literature. We first discuss our findings in light of previous research on DHH children and adolescents and then discuss their contribution to the field of emotion and mental health development in general.

Despite reduced access to emotion socialization and communication [4, 35], DHH adolescents did not differ in this study from hearing peers in their development of EA and ER skills. While previous cross-sectional research has found differences in ER skills between DHH and hearing preschoolers $[44,45]$, it is possible that some developmental gaps in ER are closed by the time the DHH kids reach adolescence, thanks to aggregated acquired experience in social interactions. Additionally, all previous adolescents' studies, which found differences between DHH and hearing peers in EA or ER [42, 46, 47], focused on participants studying at special schools for the deaf. However, children who are initially assigned to special schools often tend to have lower IQ scores compared to mainstreamed DHH peers, come from lower socioeconomic backgrounds or present additional disabilities [72, 73]. In this study as well, DHH participants enrolled in schools for the deaf presented lower levels of language scores, IQ, and parental education status, compared to their mainstreamed DHH peers (Appendix Table 9), and DHH participants in mainstream schools were overrepresented among the high-profile DHH group (in language, IQ and parental education level). Thus, school placement is likely a consequence of the students' developmental and socioeconomic profiles, and these profile differences may account to a large extent for the differences found in this study between students studying in special and mainstream schools. Preliminary analyses showed that DHH adolescents in special schools made less use of approach strategies and presented higher rates of depressive symptoms compared to the other groups. While these findings should be interpreted with caution, as they were based on exploratory analyses, it is notable that these reduced ER skills and depressive symptoms were related to profiles characterizing adolescents enrolled in special schools (see Appendix Table 11 for the correlations found in this study between approach, depressive symptoms, IQ, language skills, and parental educational status). Yet, these sociodemographic and developmental variables cannot account alone for all the differences found. Findings from post-hoc analysis indicated that while low language competency is related to higher levels of depressive symptoms, still the low-profile DHH group scored higher on depressive 
Table 6 Results of a multivariate analysis of variance for comparing the mean levels of emotion awareness, emotion regulation, and mental health symptoms between hearing and DHH participants with high or low parental education level, IQ scores, or language scores

\begin{tabular}{|c|c|c|c|c|c|c|c|c|}
\hline & & \multicolumn{2}{|l|}{ Parental education } & \multicolumn{2}{|c|}{ IQ scores } & \multicolumn{3}{|c|}{ Language scores } \\
\hline \multicolumn{2}{|c|}{$\begin{array}{l}N \\
\text { (DHH-h/DHH-1/ } \\
\text { Hear-h/ Hear-1) }\end{array}$} & $41 / 39 / 90 / 137$ & & \multicolumn{2}{|c|}{$44 / 36 / 147 / 80$} & \multicolumn{2}{|c|}{$33 / 47 / 97 / 130$} & \\
\hline Multivariate tes & & $\begin{array}{c}F(27,862.19)=1.67 \\
\boldsymbol{p}=\mathbf{0 . 0 1 8 ;} \text { Wilk's } \\
\Lambda=0.86\end{array}$ & & \multicolumn{2}{|c|}{$\begin{array}{l}F(27,862.19)=10.55 \\
p=0.036 ; \text { Wilk's } \\
\Lambda=0.87\end{array}$} & \multicolumn{3}{|c|}{$\begin{array}{l}F(27,862.19)=2.64, p<0.001 ; \text { Wilk's }^{\prime} \\
\quad \Lambda=0.79\end{array}$} \\
\hline $\begin{array}{l}\text { Dependent } \\
\text { variable } \\
\text { (Mean across } \\
\text { time points) }\end{array}$ & $F$ & $p^{\mathrm{b}}$ & & $F$ & $p^{\mathrm{b}}$ & $F$ & $p^{\mathrm{b}}$ & $\begin{array}{l}\text { Pairwise differ- } \\
\text { ences }^{c}\end{array}$ \\
\hline $\begin{array}{l}\text { Differentiating } \\
\text { emotions }\end{array}$ & 1.45 & 0.230 & & 4.53 & 0.004 & 6.47 & $<0.001$ & $\begin{array}{l}\text { DHH-h }>\text { DHH-1 } \\
\quad \text { adjusted } \\
\text { p }<0.001) ; \\
\text { DHH-h }>\text { Hear- } \\
1 \text { (adjusted } \\
\text { p }=0.028)\end{array}$ \\
\hline $\begin{array}{l}\text { Bodily una- } \\
\text { wareness }\end{array}$ & 2.98 & 0.032 & & 2.06 & 0.106 & 1.99 & 0.115 & \\
\hline $\begin{array}{l}\text { Emotion com- } \\
\text { munication }\end{array}$ & 1.64 & 0.180 & & 1.24 & 0.296 & 2.13 & 0.097 & \\
\hline $\begin{array}{l}\text { Approach } \\
\text { strategies }\end{array}$ & 3.01 & 0.030 & & 1.06 & 0.367 & 1.84 & 0.140 & \\
\hline $\begin{array}{l}\text { Avoidant strate- } \\
\text { gies }\end{array}$ & -0.95 & 0.416 & & .34 & 0.796 & .27 & 0.845 & \\
\hline $\begin{array}{l}\text { Worry/rumina- } \\
\text { tion }\end{array}$ & 0.73 & 0.537 & & 1.22 & 0.301 & 2.44 & 0.065 & \\
\hline $\begin{array}{l}\text { Depressive } \\
\text { symptoms }\end{array}$ & 4.02 & 0.008 & $\begin{array}{l}\text { Hearing- } \\
\mathrm{h}<\mathrm{DHH}-1 \\
\text { (adjusted } \\
p=0.008 \text { ) } \\
\text { Hearing- } \\
1<\mathrm{DHH}-1 \\
\text { (adjusted } \\
\mathrm{p}=0.011 \text { ) }\end{array}$ & 4.25 & 0.006 & 11.01 & $<.001$ & $\begin{array}{l}\text { DHH-h }<\text { DHH-1 } \\
\quad \text { (adjusted } \\
p<0.001 \text { ); } \\
\text { Hear-h }<\text { DHH-1 } \\
\text { (adjusted } \\
p<0.001 \text { ); } \\
\text { Hear-l }<\text { DHH-1 } \\
\text { (adjusted } \\
p=0.006 \text { ); } \\
\text { Hear-h }<\text { Hear- } \\
1 \text { (adjusted } \\
p=0.037 \text { ) }\end{array}$ \\
\hline $\begin{array}{l}\text { Anxiety symp- } \\
\text { toms }\end{array}$ & 1.08 & .357 & & 0.79 & 0.498 & 1.26 & 0.289 & \\
\hline $\begin{array}{c}\text { Externalizing } \\
\text { behaviors }\end{array}$ & 1.53 & .208 & & 1.04 & 0.375 & 4.56 & 0.004 & $\begin{array}{l}\text { Hear-h }<\text { DHH-1 } \\
\quad \text { adjusted } \\
p=0.013) ; \\
\text { Hear-h }<\text { Hear- } \\
1 \text { (adjusted } \\
p=0.010)\end{array}$ \\
\hline
\end{tabular}

$D H H-h$ DHH participants with a score higher than or equal to the median of the DHH sample, $D H H-l$ DHH participants with a score lower than the medianm Hear- $h$ hearing participants with a score higher than or equal to the median of the DHH sample, Hearing-l hearing participants with a score lower than the median. Pooled results after multiple imputations are reported

${ }^{\text {a }}$ Significance level corrected to $p<\alpha / 3=0.017$ for the three multivariate analyses being conducted

${ }^{\mathrm{b}}$ Significance level corrected to $p<\alpha / 9=0.006$ for the multiple univariate tests being conducted

${ }^{c} p$-values reported here are already adjusted by Bonferroni correction

N DHH-h / DHH-1 in [mainstream / special school]: Parental education: 41[34/7] / 39[14/25]; IQ: 44[31/13] / 36[17/19]; Language: 33[26/7] / $47[22 / 25]$ 
symptoms when compared to all other groups, including hearing participants with the same low-profile. In addition, a trend was observed for parental education, with low-profile DHH participants scoring higher on depressive symptoms when compared to both high and low-profile hearing counterparts. Possibly, personal and environmental risk factors such as low language competency, or low parental education, which is also related to low household income, exert differential impact when the child has fewer internal or external resources to rely on [74]. Such factors may further impinge upon DHH adolescents' access to communication, while at the same time the DHH adolescent has less opportunities to compensate by turning to alternative social circles. Future studies need to further explore the differential role of factors such as low socioeconomic background in the formation of depression in DHH adolescents, and in the longitudinal development of emotion skills and mental health over time.

While findings suggested that developmental and socioeconomic profiles may explain the differences found between students in special and in mainstream schools, other factors may also contribute, such as an acquired sense of helplessness [43] or life-long coping with stigmatic attitudes [49]. These factors may not stem from the educational-settings themselves, but from the interaction between the personal profiles of students assigned to special education and the attitudes within their families, educational environments and the larger society. Research with DHH adolescents needs to clarify the unique contexts faced by those studying in special education beyond deafness and educational placement per-se [75] in order to better understand their emotional development and needs.

Regarding DHH adolescents who study in mainstream schools, an increasing body of research has shown that they may experience socio-emotional difficulties [e.g., reviews at 76, 77]. Our findings suggested that these children's EA and ER skills were developed to the same extent as in their hearing peers. Future research may, therefore, benefit from focusing on environmental factors at schools, such as adaptation of peers to their communication needs or social stigma [77, 78], in trying to further understand these difficulties.

The longitudinal design of this study uniquely enabled to examine the development and unique contributions of specific EA and ER strategies in light of knowledge gained from previous cross-sectional research. For all our adolescent participants, findings showed no developmental trends for EA skills and avoidant ER, an increase in approach ER, and a decrease in worry/rumination over an 18-month period. These findings partly support previous cross-sectional research [see review at 49], suggesting that during adolescence the ability to cope adaptively with emotional stress increases with age.
In line with previous studies on adolescents' depression [e.g., 2, 16], our findings regarding EA confirmed that adolescents with an initial high ability to differentiate between emotions and to locate their antecedents, or those who showed an increase in this ability, also showed a decrease in depressive symptoms over an 18 -months period. Furthermore, findings provided a first longitudinal support for the similar contribution of emotion communication with other people to a decrease in depressive symptoms [e.g., 10, 19 for cross-sectional findings]. Notably, these EA skills retained their relations to depression also after controlling for the effects of ER, thereby pointing at their unique longitudinal contribution. Unexpectedly, EA skills were unrelated to the development of anxiety, possibly because parent reports were used instead of self-reports as in previous studies [e.g., $10,19]$ (see Limitations). In addition, contrary to our expectations bodily unawareness was not related to internalizing symptoms, but high baseline levels of bodily unawareness were related to higher levels of externalizing symptoms over time. While bodily unawareness was positively correlated with emotion differentiation and communication, in line with previous research (Appendix Table 7, see also, e.g., [9, 19]), our findings suggest that bodily unawareness may have a differentiated prediction with regards to the development of mental health symptoms.

Our findings provided longitudinal support to crosssectional research on emotion regulation strategies [e.g., $13,22]$, showing that high levels and increasing levels of approach and avoidance ER are related to a decrease in depressive symptoms over time. Interestingly, only an increase in approach ER was related to a decrease in anxiety symptoms. Possibly, the active stance involved in approaching the stressor prevents the generation of anxiety by increasing a sense of control over the situation. It is also possible that decisions over which regulation strategies to use are made according to the perceived controllability of the stressors [25], with perception of stressors as controllable leading both to low anxiety level and adopting an approaching stance.

As expected, worry/rumination was positively related to the development of depressive, anxiety, and externalizing symptoms over time. These findings support the strong explanatory power of worry/rumination as a core transdiagnostic factor underlying both internalizing and externalizing symptoms in adolescents [e.g., 27]. While the predictive link between worry/rumination and aggressive or disruptive behaviors has been examined so far only for boys [28, 29], this study showed that gender did not moderate this effect.

Last, emotion differentiation, emotion communication, approach and avoidance ER, and worry/rumination all contributed to the development of depressive symptoms both in their baseline levels and in their within-person change scores over time, or solely in their change scores in the case of 
anxiety or externalizing symptoms. These findings highlight that these emotion skills can change over time in individual adolescents and may, therefore, be subject to change. Furthermore, decreases or increases in these skills can serve as warning signs for future development of mental health symptoms and at the same time may suggest the most suitable focus for mental health interventions, benefitting adolescents with and without hearing loss alike.

\section{Limitations}

This study examined several aspects of EA and ER which had been relatively well-researched in previous literature. However, there is a wide range of emotion skills which could yield different results and thus need further examination for their unique contributions. The sample sizes applied in this study were adequate for longitudinal comparison between DHH and hearing participants, but they did not allow for longitudinal comparisons within the DHH group. Larger sample sizes would allow for exploring in more depth the moderating role of factors such as educational placement, teachers' attitudes toward deafness, developmental factors, socio-economic background or family interactions. Qualitative methods, as well as including more DHH researchers and community members in research planning and conduction, can further enrich our understanding by 'insider' perspectives on factors influencing emotion and mental health development in different contexts. Next, levels and variance of externalizing symptoms were low for all our participants. Future studies would, therefore, benefit from assessing externalizing behaviors in larger sample sizes of various populations to confirm, for instance, the lack of a gender effect in this study on the relation between worry/rumination and externalizing symptoms. The use in this study of different informants to measure the outcomes may have reduced the power to detect associations between self-reported predictors and parent-reported outcomes, such as the lack of a significant relation in this study between EA and anxiety. On the other hand, findings question the validity of associations found when only self-reports were used. Future designs, which use multi-informants per each variable, can better examine the extent to which associations in the field of EA, ER and mental health are inflated due to commonmethod bias [13].

\section{Conclusion}

This study provided a longitudinal support for the importance of several aspects of EA and ER during adolescence, by showing their unique contributions to mental health development also after controlling for each other's effects. Findings showed that decreases in certain emotion skills during adolescence might be warning signs to subsequent development of mental health symptoms. It is suggested that interventions tailored at specific emotion skills would be beneficial for prevention of distinguished mental health symptoms. Overall, findings pointed at the relative positive situation of adolescents with and without hearing loss alike, in their EA and ER development. Exploratory analyses suggested that DHH students in special schools for the deaf may be at risk for their ER and mental health development; that these differences are likely explained by specific developmental and socio-economic profiles of students assigned to special education; and that language competency and possibly also parental education level may exert a differential impact on mental health depending on the hearing status of the child. Future research needs to address the heterogeneity within the DHH population and its possible interaction with different risk factors in both cross-sectional and longitudinal designs.

\section{Appendix}

See Appendix Tables 7, 8, 9, 10, 11

Funding The project was supported by the Innovational Research Incentives Scheme (a VIDI grant) by The Netherlands Organization for Scientific Research (NOW), grant no. 452-07-004 to Carolien Rieffe; and by the European Union's Horizon 2020 research and innovation 


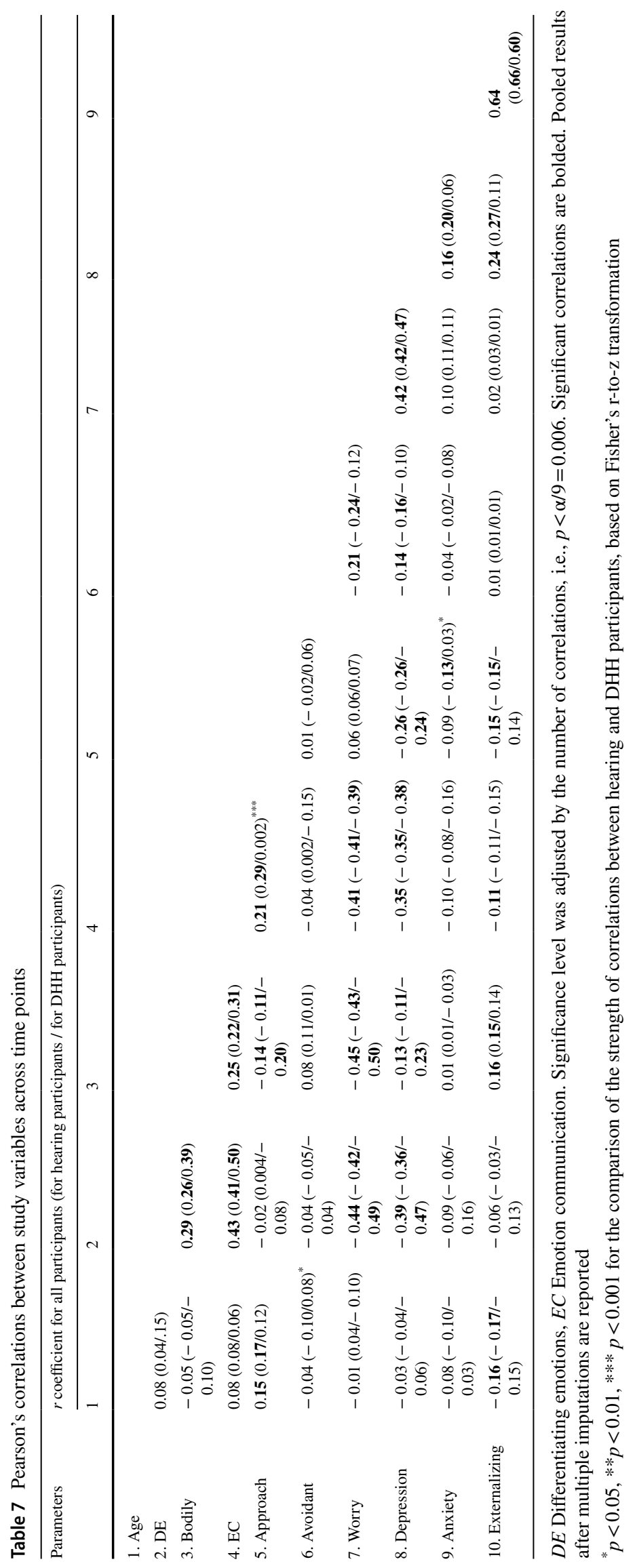


Table 8 Overview of missing data

\begin{tabular}{|c|c|c|c|c|c|c|}
\hline & \multicolumn{3}{|c|}{ DHH } & \multicolumn{3}{|c|}{ Hearing } \\
\hline & \multirow[t]{2}{*}{$N$} & \multicolumn{2}{|c|}{ Missing } & \multirow[t]{2}{*}{$N$} & \multicolumn{2}{|c|}{ Missing } \\
\hline & & Count & $\%$ & & Count & $\%$ \\
\hline \multicolumn{7}{|l|}{ Time 1} \\
\hline Age & 80 & 0 & 0 & 227 & 0 & 0 \\
\hline Gender & 80 & 0 & 0 & 227 & 0 & 0 \\
\hline IQ scores & 77 & 3 & 4 & 199 & 28 & 12 \\
\hline Language scores & 54 & 26 & 33 & 196 & 31 & 14 \\
\hline Maternal education level & 67 & 13 & 16 & 164 & 63 & 28 \\
\hline Paternal education level & 68 & 12 & 15 & 160 & 67 & 30 \\
\hline Differentiating emotions & 79 & 1 & 1 & 227 & 0 & 0 \\
\hline Bodily unawareness & 79 & 1 & 1 & 227 & 0 & 0 \\
\hline Emotion communication & 79 & 1 & 1 & 227 & 0 & 0 \\
\hline Approach strategies & 80 & 0 & 0 & 227 & 0 & 0 \\
\hline Avoidant strategies & 80 & 0 & 0 & 227 & 0 & 0 \\
\hline Worry/rumination & 79 & 1 & 1 & 227 & 0 & 0 \\
\hline Depressive symptoms & 79 & 1 & 1 & 227 & 0 & 0 \\
\hline Anxiety symptoms & 71 & 9 & 11 & 183 & 44 & 19 \\
\hline Externalizing behaviors & 71 & 9 & 11 & 183 & 44 & 19 \\
\hline \multicolumn{7}{|l|}{ Time 2} \\
\hline Age & 78 & 2 & 3 & 198 & 29 & 13 \\
\hline Differentiating emotions & 78 & 2 & 3 & 196 & 31 & 14 \\
\hline Bodily unawareness & 78 & 2 & 3 & 196 & 31 & 14 \\
\hline Emotion communication & 78 & 2 & 3 & 196 & 31 & 14 \\
\hline Approach strategies & 78 & 2 & 3 & 197 & 30 & 13 \\
\hline Avoidant strategies & 78 & 2 & 3 & 197 & 30 & 13 \\
\hline Worry/rumination & 78 & 2 & 3 & 197 & 30 & 13 \\
\hline Depressive symptoms & 78 & 2 & 3 & 198 & 29 & 13 \\
\hline Anxiety symptoms & 59 & 21 & 26 & 170 & 57 & 25 \\
\hline Externalizing behaviors & 59 & 21 & 26 & 170 & 57 & 25 \\
\hline \multicolumn{7}{|l|}{ Time 3} \\
\hline Age & 63 & 17 & 21 & 166 & 61 & 27 \\
\hline Differentiating emotions & 64 & 16 & 20 & 166 & 61 & 27 \\
\hline Bodily unawareness & 64 & 16 & 20 & 166 & 61 & 27 \\
\hline Emotion communication & 64 & 16 & 20 & 166 & 61 & 27 \\
\hline Approach strategies & 64 & 16 & 20 & 166 & 61 & 27 \\
\hline Avoidant strategies & 64 & 16 & 20 & 166 & 61 & 27 \\
\hline Worry/rumination & 63 & 17 & 21 & 166 & 61 & 27 \\
\hline Depressive symptoms & 64 & 16 & 20 & 166 & 61 & 27 \\
\hline Anxiety symptoms & 49 & 31 & 39 & 142 & 85 & 37 \\
\hline Externalizing behaviors & 49 & 31 & 39 & 142 & 85 & 37 \\
\hline
\end{tabular}

DHH Deaf or hard of hearing 
Table 9 Mean scores (standard deviations) of study variables and group comparisons at each time point between DHH participants attending mainstream schools and DHH participants attending special education schools

\begin{tabular}{|c|c|c|c|c|}
\hline & \multicolumn{2}{|l|}{ Mean (SD) } & \multirow[t]{2}{*}{$t$-value $\mathrm{a}^{\mathrm{a}}$} & \multirow[t]{2}{*}{$p$-value ${ }^{\mathrm{a}}$} \\
\hline & Mainstream & Special & & \\
\hline \multicolumn{5}{|l|}{ Personal characteristics } \\
\hline No. of participants & 48 & 32 & - & - \\
\hline Age at Time 1 & $143.85(20.15)$ & $141.53(18.58)$ & 0.52 & 0.602 \\
\hline Language scores & $10.94(2.91)$ & $6.5(3.01)$ & 3.32 & 0.002 \\
\hline IQ scores & $10.78(2.76)$ & $9.28(2.28)$ & 2.42 & 0.016 \\
\hline Parental education level & $3.45(0.63)$ & $2.8(0.71)$ & 3.08 & 0.004 \\
\hline \multicolumn{5}{|l|}{ Time 1} \\
\hline Differentiating emotions & $2.36(0.47)$ & $2.22(0.42)$ & 1.29 & 0.199 \\
\hline Bodily unawareness & $1.89(0.47)$ & $2.08(0.37)$ & -1.77 & 0.077 \\
\hline Emotion communication & $2.11(0.40)$ & $2.11(0.33)$ & 0.07 & 0.948 \\
\hline Approach strategies & $2.24(0.34)$ & $1.88(0.32)$ & 4.86 & $<0.001$ \\
\hline Avoidant strategies & $1.86(0.43)$ & $1.87(0.36)$ & -0.09 & 0.932 \\
\hline Worry/rumination & $1.95(0.50)$ & $1.86(.45)$ & 0.72 & 0.469 \\
\hline Depressive symptoms & $1.33(0.20)$ & $1.46(0.20)$ & -2.90 & 0.004 \\
\hline Anxiety symptoms & $1.57(0.45)$ & $1.41(0.48)$ & 1.06 & 0.291 \\
\hline Externalizing behaviors & $1.40(0.21)$ & $1.41(0.20)$ & -0.35 & 0.730 \\
\hline \multicolumn{5}{|l|}{ Time 2} \\
\hline Differentiating emotions & $2.41(0.42)$ & $2.34(0.43)$ & 0.74 & 0.459 \\
\hline Bodily unawareness & $1.98(0.47)$ & $2.15(0.38)$ & -1.65 & 0.099 \\
\hline Emotion communication & $2.08(0.42)$ & $2.12(0.33)$ & -0.47 & 0.639 \\
\hline Approach strategies & $2.29(.40)$ & $1.95(0.44)$ & 3.49 & $<0.001$ \\
\hline Avoidant strategies & $2.02(0.46)$ & $1.83(0.39)$ & 1.93 & 0.054 \\
\hline Worry/rumination & $1.76(0.49)$ & $1.78(036)$ & -0.18 & 0.861 \\
\hline Externalizing behaviors & $1.32(0.21)$ & $1.35(0.21)$ & -0.48 & 0.631 \\
\hline Anxiety symptoms & $1.45(.38)$ & $1.43(0.38)$ & 0.14 & 0.888 \\
\hline Depressive symptoms & $1.32(0.19)$ & $1.41(0.19)$ & -2.08 & .037 \\
\hline \multicolumn{5}{|l|}{ Time 3} \\
\hline Differentiating emotions & $2.44(0.48)$ & $2.50(0.42)$ & -0.52 & 0.602 \\
\hline Bodily unawareness & $1.85(0.55)$ & $2.13(0.41)$ & -2.17 & $\mathbf{0 . 0 3 0}$ \\
\hline Emotion communication & $2.16(0.44)$ & $2.26(0.34)$ & -0.95 & 0.342 \\
\hline Approach strategies & $2.33(0.39)$ & $2.09(0.41)$ & 2.41 & 0.016 \\
\hline Avoidant strategies & $2.03(0.37)$ & $1.98(0.33)$ & .48 & 0.629 \\
\hline Worry/rumination & $1.76(0.49)$ & $1.66(0.33)$ & .89 & 0.372 \\
\hline Depressive symptoms & $1.29(0.18)$ & $1.38(0.20)$ & -1.90 & 0.057 \\
\hline Anxiety symptoms & $1.52(0.42)$ & $1.37(0.23)$ & 1.24 & 0.217 \\
\hline Externalizing behaviors & $1.35(0.22)$ & $1.33(0.17)$ & 0.41 & 0.682 \\
\hline
\end{tabular}

Significant results are in bold

$D H H$ Deaf or hard of hearing, $S D$ Standard deviation

${ }^{\text {a}}$ Pooled results after multiple imputations 
Table 10 Pearson's correlations between predictor and outcome variables across time points in DHH participants attending mainstream schools (DHHm), DHH participants attending special education schools (DHHs), and hearing participants

\begin{tabular}{|c|c|c|c|}
\hline \multirow[t]{2}{*}{ Predictor variable } & \multicolumn{3}{|c|}{$\begin{array}{l}\text { Correlation }(r) \text { with outcome variable } \\
\text { (DHHm / DHHs / hearing) }\end{array}$} \\
\hline & Depressive symptoms & Anxiety symptoms & Externalizing behaviors \\
\hline Differentiating & $-0.49 /-0.45 /-0.36$ & $-0.21 /-0.11 /-.06$ & $-0.17 /-0.02 /-0.03$ \\
\hline Bodily unawareness & $-0.32^{\mathrm{a}} /-0.30^{\mathrm{ab}} /-0.11^{\mathrm{b}}$ & $-0.04 / 0.07 / 0.01$ & $0.06 / 0.34 / 0.15$ \\
\hline Communication & $-0.41 /-0.41 /-0.35$ & $-0.20 /-0.06 /-0.08$ & $-\mathbf{0 . 2 4 ^ { \mathrm { a } }} / 0.09^{\mathrm{b}} /-\mathbf{0 . 1 1} 1^{\mathrm{ab}}$ \\
\hline Approach & $-0.08^{\mathrm{a}} /-\mathbf{0 . 2 6}^{\mathrm{ab}} /-.26^{\mathrm{b}}$ & $0.05 /-0.10 /-\mathbf{0 . 1 3}$ & $-0.02^{\mathrm{a}} /-\mathbf{0 . 3 3} 3^{\mathrm{b}} /-\mathbf{0 . 1 5}{ }^{\mathrm{ab}}$ \\
\hline Avoidant & $-0.09 /-0.07 /-0.16$ & $-0.16 / 0.05 /-0.02$ & $0.06 /-0.07 / 0.01$ \\
\hline Worry & $0.48 / 0.57 / 0.42$ & $0.11 / 0.09 / 0.11$ & $0.06 /-0.09 / 0.03$ \\
\hline
\end{tabular}

Significance level was adjusted by the number of correlations each predictor was in, i.e., $p<\alpha / 3=0.017$. Significant correlations are bolded. Pooled results after multiple imputations are reported

The character superscripts (i.e., ${ }^{a},{ }^{b}$ ) denote a difference in the strength of correlations between the three groups at $p<0.05$, based on Fisher's $r$-to- $z$ transformation. When the superscripts differ, the groups differ in the strength of correlation. When the superscripts are the same or when there is no superscript, the groups do not differ

\begin{tabular}{llll}
\hline Personal variable & \multicolumn{2}{l}{$r$ coefficient for all participants (for hearing participants / for DHH participants) } \\
\cline { 2 - 4 } & Parental education & Language & Nonverbal IQ \\
\hline Differentiating emotions & $0.05(-0.03 / \mathbf{0 . 2 2})^{* *}$ & $\mathbf{0 . 1 4}(\mathbf{0 . 1 2} / 0.18)$ & $\mathbf{0 . 1 6}(\mathbf{0 . 1 4} / \mathbf{0 . 2 0})$ \\
Bodily unawareness & $-0.03(-0.06 / 0.06)$ & $-0.08(-0.04 /-0.13)$ & $0.01(0.04 /-0.05)$ \\
Emotion communication & $-0.01(-0.07 / .14)^{* *}$ & $.03(.03 / .06)$ & $-0.01(-0.01 / 0.02)$ \\
Approach strategies & $0.09(0.03 / \mathbf{0 . 2 4})^{* *}$ & $\mathbf{0 . 1 9}(\mathbf{0 . 1 5} / \mathbf{0 . 2 7})$ & $0.06(0.01 / 0.15)$ \\
Avoidant strategies & $-0.07(-0.08 /-0.03)$ & $0.02(-0.01 / 0.08)$ & $-0.02(0.01 /-0.09)$ \\
Worry/rumination & $0.01(0.06 /-0.13)^{*}$ & $-0.06(-0.06 /-0.07)$ & $-0.06(-0.07 /-0.06)$ \\
Depressive symptoms & $-0.07(0.00 / \mathbf{- 0 . 2 2})^{* *}$ & $\mathbf{- 0 . 2 3}(-\mathbf{0 . 1 8} / \mathbf{- 0 . 3 0})$ & $\mathbf{- 0 . 1 3}(-\mathbf{0 . 1 0} /-\mathbf{0 . 1 7})$ \\
Anxiety symptoms & $0.01(0.05 /-0.08)$ & $\mathbf{- 0 . 0 3 ( - 0 . 0 9 / 0 . 1 1 ) *}$ & $-0.01(-0.01 /-0.01)$ \\
Externalizing behaviors & $0.01(0.06 /-0.14)^{*}$ & $\mathbf{- 0 . 1 7}(-\mathbf{0 . 2 1} / \mathbf{- 0 . 0 5})$ & $-0.01(0.02 /-0.05)$ \\
\hline
\end{tabular}

Significance level was adjusted by the number of correlations each predictor was in, i.e., $p<\alpha / 3=.017$. Significant correlations are bolded. Pooled results after multiple imputations are reported

${ }^{*} p<.05, * * p<.01$ for the comparison of the strength of correlations between hearing and DHH participants, based on Fisher's r-to-z transformation
Table 11 Pearson's correlations between study variables and parental education level, language scores, and nonverbal IQ across time point
Consent to publish Not applicable.

program under the Marie Skłodowska-Curie grant agreement, grant no. 707404 to Adva Eichengreen.

Data availability The dataset and associated information used in the current study will be archived on the Leiden University archiving platform DataverseNL (https://dataverse.nl/) once the manuscript is accepted. https://doi.org/10.34894/U2LD88

Code availability Not applicable.

\section{Declarations}

Conflict of interests The authors have no relevant financial or nonfinancial interests to disclose.

Ethics approval Approval was obtained from the ethics committee of Leiden University. The procedures used in this study adhere to the tenets of the Declaration of Helsinki.

Consent to participate Written informed consent was obtained from the parents.
Open Access This article is licensed under a Creative Commons Attribution 4.0 International License, which permits use, sharing, adaptation, distribution and reproduction in any medium or format, as long as you give appropriate credit to the original author(s) and the source, provide a link to the Creative Commons licence, and indicate if changes were made. The images or other third party material in this article are included in the article's Creative Commons licence, unless indicated otherwise in a credit line to the material. If material is not included in the article's Creative Commons licence and your intended use is not permitted by statutory regulation or exceeds the permitted use, you will need to obtain permission directly from the copyright holder. To view a copy of this licence, visit http://creativecommons.org/licenses/by/4.0/. 


\section{References}

1. Sheppes G, Suri G, Gross JJ (2015) Emotion regulation and psychopathology. Annu Rev Clin Psychol 11:379-405. https://doi. org/10.1146/annurev-clinpsy-032814-112739

2. Rieffe C, De Rooij M (2012) The longitudinal relationship between emotion awareness and internalising symptoms during late childhood. Eur Child Adolesc Psychiatry 21:349-356. https:// doi.org/10.1007/s00787-012-0267-8

3. Morris AS, Silk JS, Steinberg L, Myers SS, Robinson LR (2007) The role of the family context in the development of emotion regulation. Soc Dev 16:361-388. https://doi.org/10.1111/j.14679507.2007.00389.x

4. Rieffe C, Netten AP, Broekhof E, Veiga G (2015) The Role of the Environment in Children's Emotion Socialization. Educ Deaf Learn 369-388. https://doi.org/10.1093/acprof:oso/9780190215 194.003.0016

5. Stevenson J, Kreppner J, Pimperton H, Worsfold S, Kennedy C (2015) Emotional and behavioural difficulties in children and adolescents with hearing impairment: a systematic review and meta-analysis. Eur Child Adolesc Psychiatry 24:477-496. https:// doi.org/10.1007/s00787-015-0697-1

6. Theunissen SCPM, Rieffe C, Netten AP, Briaire JJ, Soede W, Schoones JW, Frijns JHM (2014) Psychopathology and its risk and protective factors in hearing-impaired children and adolescents a systematic review. JAMA Pediatr 168:170-177. https:// doi.org/10.1001/jamapediatrics.2013.3974

7. Lambie JA, Marcel AJ (2002) Consciousness and the varieties of emotion experience: a theoretical framework. Psychol Rev 109:219-259. https://doi.org/10.1037/0033-295X.109.2.219

8. Sendzik L, Schäfer JÖ, Samson AC, Naumann E, TuschenCaffier B (2017) Emotional awareness in depressive and anxiety symptoms in youth: a meta-analytic review. J Youth Adolesc 46:687-700. https://doi.org/10.1007/s10964-017-0629-0

9. Rieffe C, Oosterveld P, Miers AC, Meerum Terwogt M, Ly $\mathrm{V}$ (2008) Emotion awareness and internalising symptoms in children and adolescents: the emotion awareness questionnaire revised. Pers Individ Dif 45:756-761. https://doi.org/10.1016/j. paid.2008.08.001

10. Mathews BL, Koehn AJ, Abtahi MM, Kerns KA (2016) Emotional competence and anxiety in childhood and adolescence: a meta-analytic review. Clin Child Fam Psychol Rev 19:162-184. https://doi.org/10.1007/s10567-016-0204-3

11. Paus T, Keshavan M, Giedd JN (2008) Why do many psychiatric disorders emerge during adolescence? Nat Rev Neurosci 9:947-957. https://doi.org/10.1038/nrn2513

12. Riediger M, Klipker K (2014) Emotion regulation in adolescence. In: Gross JJ (ed) Handbook of emotion regulation, 2nd edn. The Guilford Press, New York, pp 187-202

13. Compas BE, Jaser SS, Bettis AH, Watson KH, Gruhn MA, Dunbar JP, Williams E, Thigpen JC (2017) Coping, emotion regulation, and psychopathology in childhood and adolescence: a meta-analysis and narrative review. Psychol Bull 143:939-991. https://doi.org/10.1037/bul0000110

14. Hampel P, Petermann F (2005) Age and gender effects on coping in children and adolescents. J Youth Adolesc 34:73-83. https://doi.org/10.1007/s10964-005-3207-9

15. Mavroveli S, Petrides KV, Rieffe C, Bakker F (2007) Trait emotional intelligence, psychological well-being and peer-rated social competence in adolescence. Br J Dev Psychol 25:263275. https://doi.org/10.1348/026151006X118577

16. Nyquist AC, Luebbe AM (2020) An emotion recognition-awareness vulnerability hypothesis for depression in adolescence: a systematic review. Clin Child Fam Psychol Rev 23:27-53. https://doi.org/10.1007/s10567-019-00302-3
17. O'Toole MS, Hougaard E, Mennin DS (2013) Social anxiety and emotion knowledge: a meta-analysis. J Anxiety Disord 27:98-108. https://doi.org/10.1016/j.janxdis.2012.09.005

18. Penza-Clyve S, Zeman J (2002) Initial validation of the emotion expression scale for children (EESC). J Clin Child Adolesc Psychol 31:540-547. https://doi.org/10.1207/S15374424JCCP3104_ 12

19. Rueth JE, Lohaus A, Vierhaus M (2019) The German version of the emotion awareness questionnaire for children and adolescents: associations with emotion regulation and psychosocial adjustment. J Pers Assess 101:434-445. https://doi.org/10.1080/00223 891.2018.1492414

20. Flynn M, Rudolph KD (2014) A prospective examination of emotional clarity, stress responses, and depressive symptoms during early adolescence. J Early Adolesc 34:923-939. https://doi.org/ 10.1177/0272431613513959

21. Factor PI, Rosen PJ, Reyes RA (2016) The relation of poor emotional awareness and externalizing behavior among children with ADHD. J Atten Disord 20:168-177. https://doi.org/10.1177/ 1087054713494005

22. Schäfer JÖ, Naumann E, Holmes EA, Tuschen-Caffier B, Samson AC (2017) Emotion regulation strategies in depressive and anxiety symptoms in youth: a meta-analytic review. J Youth Adolesc 46:261-276. https://doi.org/10.1007/s10964-016-0585-0

23. Wright M, Banerjee R, Hoek W, Rieffe C, Novin S (2010) Depression and social anxiety in children: differential links with coping strategies. J Abnorm Child Psychol 38:405-419. https://doi.org/ 10.1007/s10802-009-9375-4

24. Garnefski N, Kraaij V (2007) The cognitive emotion regulation questionnaire: Psychometric features and prospective relationships with depression and anxiety in adults. Eur J Psychol Assess 23:141-149. https://doi.org/10.1027/1015-5759.23.3.141

25. Vera E, Vacek K, Coyle L, Stinson J, Mull M, Doud K, Buchheit C, Gorman C, Hewitt A, Keene C, Blackmon S, Langrehr K (2011) An examination of culturally relevant stressors, coping, ethnic Identity, and subjective well-being in urban, ethnic minority adolescents. Prof Sch Couns 15:55-66. https://doi.org/ 10.5330/psc.n.2011-15.55

26. Pouw LBC, Rieffe C, Stockmann L, Gadow KD (2013) The link between emotion regulation, social functioning, and depression in boys with ASD. Res Autism Spectr Disord 7:549-556. https:// doi.org/10.1016/j.rasd.2013.01.002

27. Aldao A, Gee DG, De Los RA, Seager I (2016) Emotion regulation as a transdiagnostic factor in the development of internalizing and externalizing psychopathology: current and future directions. Dev Psychopathol 28:927-946. https://doi.org/10.1017/S0954 579416000638

28. McLaughlin KA, Aldao A, Wisco BE, Hilt LM (2014) Rumination as a transdiagnostic factor underlying transitions between internalizing symptoms and aggressive behavior in early adolescents. $\mathrm{J}$ Abnorm Psychol 123:13-23. https://doi.org/10.1037/a0035358

29. Bos MGN, Diamantopoulou S, Stockmann L, Begeer S, Rieffe C (2018) Emotion control predicts internalizing and externalizing behavior problems in boys with and without an autism spectrum disorder. J Autism Dev Disord 48:2727-2739. https://doi.org/10. 1007/s10803-018-3519-8

30. Barrett LF, Gross J, Christensen TC, Benvenuto M (2001) Knowing what you're feeling and knowing what to do about it: mapping the relation between emotion differentiation and emotion regulation. Cogn Emot 15:713-724. https://doi.org/10.1080/0269993014 3000239

31. Hatzenbuehler ML, McLaughlin KA, Nolen-Hoeksema S (2008) Emotion regulation and internalizing symptoms in a longitudinal study of sexual minority and heterosexual adolescents. J Child Psychol Psychiatry 49:1270-1278. https://doi.org/10.1111/j.14697610.2008.01924.x 
32. McLaughlin KA, Hatzenbuehler ML, Mennin DS, Nolen-Hoeksema S (2011) Emotion dysregulation and adolescent psychopathology: a prospective study. Behav Res Ther 49:544-554. https:// doi.org/10.1016/j.brat.2011.06.003

33. Mazzone A, Camodeca M (2018) Emotion awareness and somatic complaints in preadolescence: the mediating role of coping strategies. Infant Child Dev 27:1-13. https://doi.org/10.1002/icd.2075

34. Berkowitz MC, Jonas JA (2014) Deaf and hearing siblings in conversations. McFarland \& Company Inc, Jefferson, North Carolina

35. Calderon R, Greenberg MT (2012) Social and emotional development of deaf children: Family, school, and program effects. In: Marschark M, Spencer PE (eds) Oxford Handbook of deaf studies, language and education, $2^{\text {nd }}$ edn (vol 1). Oxford University Press. https://doi.org/10.1093/oxfordhb/9780199750986.013.0014.

36. Brown PM, Cornes A (2015) Mental health of deaf and hardof-hearing adolescents: What the students say. J Deaf Stud Deaf Educ 20:75-81. https://doi.org/10.1093/deafed/enu031

37. Fellinger J, Holzinger D, Sattel H, Laucht M (2008) Mental health and quality of life in deaf pupils. Eur Child Adolesc Psychiatry 17:414-423. https://doi.org/10.1007/s00787-008-0683-y

38. Netten AP, Rieffe C, Theunissen SCPM, Soede W, Dirks E, Korver AMH, Konings S, Oudesluys-Murphy AM, Dekker FW, Frijns JHM (2015) Early identification: Language skills and social functioning in deaf and hard of hearing preschool children. Int J Pediatr Otorhinolaryngol 79:2221-2226. https://doi. org/10.1016/j.ijporl.2015.10.008

39. Stevenson J, Pimperton H, Kreppner J, Worsfold S, Terlektsi E, Kennedy C (2017) Emotional and behaviour difficulties in teenagers with permanent childhood hearing loss. Int J Pediatr Otorhinolaryngol 101:186-195. https://doi.org/10.1016/j.ijporl. 2017.07.031

40. Wong CL, Ching TY, Leigh G, Cupples L, Button L, Marnane V, Whitfield J, Gunnourie M, Martin L (2018) Psychosocial development of 5-year-old children with hearing loss: Risks and protective factors. Int J Audiol 57:S81-S92. https://doi.org/10. 1080/14992027.2016.1211764

41. Freeman V, Pisoni DB, Kronenberger WG, Castellanos I (2017) Speech intelligibility and psychosocial functioning in deaf children and teens with cochlear implants. J Deaf Stud Deaf Educ 22:278-289. https://doi.org/10.1093/deafed/enx001

42. Rieffe C (2012) Awareness and regulation of emotions in deaf children. Br J Dev Psychol 30:477-492. https://doi.org/10. 1111/j.2044-835X.2011.02057.x

43. Rieffe C, Terwogt MM, Smit C (2003) Deaf children on the causes of emotions. Educ Psychol 23:159-168. https://doi.org/ 10.1080/01443410303229

44. Wiefferink CH, Rieffe C, Ketelaar L, Frijns JHM (2012) Predicting social functioning in children with a cochlear implant and in normal-hearing children: the role of emotion regulation. Int $\mathrm{J}$ Pediatr Otorhinolaryngol 76:883-889. https://doi.org/10.1016/j. ijporl.2012.02.065

45. Wiefferink CH, Rieffe C, Ketelaar L, De Raeve L, Frijns JHM (2013) Emotion understanding in deaf children with a cochlear implant. J Deaf Stud Deaf Educ 18:175-186. https://doi.org/10. 1093/deafed/ens042

46. Eschenbeck H, Gillé V, Heim-Dreger U, Schock A, Schott A (2017) Daily stress, hearing-specific stress and coping: selfreports from deaf or hard of hearing children and children with auditory processing disorder. J Deaf Stud Deaf Educ 22:49-58. https://doi.org/10.1093/deafed/enw053

47. Rieffe C, Terwogt MM (2006) Anger communication in deaf children. Cogn Emot 20:1261-1273. https://doi.org/10.1080/ 02699930500513502

48. Zimmer-Gembeck MJ, Skinner EA (2011) The development of coping across childhood and adolescence: an integrative review and critique of research. Int J Behav Dev 35:1-17. https://doi. org/10.1177/0165025410384923

49. Mejstad L, Heiling K, Svedin CG (2008) Mental health and self-image among deaf and hard of hearing children. Am Ann Deaf 153:504-515. https://doi.org/10.1353/aad.0.0069

50. Eichengreen A, Broekhof E, Güroğlu B, Rieffe C (2020) Fairness decisions in children and early adolescents with and without hearing loss. Soc Dev 29: 888-902. https://onlinelibrary. wiley.com/doi/full/https://doi.org/10.1111/sode.12423

51. Broekhof E, Bos MGN, Camodeca M, Rieffe C (2018) Longitudinal associations between bullying and emotions in deaf and hard of hearing adolescents. J Deaf Stud Deaf Educ 23:17-27. https://doi.org/10.1093/deafed/enx036

52. Kouwenberg M, Rieffe C, Theunissen SC (2011) Intrapersonal and interpersonal factors related to self reported symptoms of depression in DHH youth. Int J Mental Health Deaf 1:46-57

53. Theunissen SC, Rieffe C, Kouwenberg M, Soede W, Briaire JJ, Frijns JHM (2011) Depression in hearing-impaired children. Int J Pediatr Otorhinolaryngol 75:1313-1317

54. Rieffe C, Broekhof E, Eichengreen A, Kouwenberg M, Veiga G, da Silva BM, van der Laan A, Frijns JHM (2018) Friendship and emotion control in pre-adolescents with or without hearing loss. J Deaf Stud Deaf Educ 23:209-218. https://doi.org/10. 1093/deafed/eny012

55. Kort DW, Compaan EL, Bleichrodt N, Resing WCM, Schittekatte M, Bosmans M, ... Verhaeghe P (2002) WISC-II NL handleiding. Dutch Manual). NIP: Amsterdam.)

56. Wechsler D (2012) Wechsler Intelligence Scale for. Children. https://doi.org/10.1007/springerreference_184296

57. Kort W, Schittekatte M, Compaan E (2008) CELF-4-NL: clinical evaluation of language fundamentals. Amsterdam Pearson Assess. Inf, Amsterdam

58. Rieffe C, De Bruine M, De Rooij M, Stockmann L (2014) Approach and avoidant emotion regulation prevent depressive symptoms in children with an Autism Spectrum Disorder. Int J Dev Neurosci 39:37-43. https://doi.org/10.1016/j.ijdevneu. 2014.06.003

59. Jellesma FC, Meerum Terwogt M, Reijntjes AH, Rieffe CJ, Stegge H (2005) De vragenlijst Non-Productieve Denkprocessen voor Kinderen (npdk). Kind En Adolescent 26:171-177. https://doi.org/10.1007/bf03060964

60. Kovacs M (2003) The children's depression inventory (CDI). Multi-Health System, Toronto

61. Timbremont B, Braet C, Roelofs J (2002) Children's depression inventory: Nederlandstalige versie. Swets \& Zeitlinger, Lisse

62. Gadow KD, Sprafkin J (1994) Child Symptom Inventories manual. Stony Brook: Checkmate Plus.

63. Theunissen SCPM, Rieffe C, Kouwenberg M, De Raeve L, Soede W, Briaire JJ, Frijns JHM (2012) Anxiety in children with hearing aids or cochlear implants compared to normally hearing controls. Laryngoscope 122:654-659. https://doi.org/ 10.1002/lary.22502

64. Singer JD, Willett JB (2003). Applied longitudinal data analysis: Modeling change and event occurrence. Oxford University Press, New York

65. Akaike H (1974) A new look at statistical-model identification. IEEE Trans Automat Contr 19:716-723

66. Schwarz G (1978) Estimating the dimension of a model. Ann Stat 6:461-464. https://doi.org/10.1214/aos/1176344136

67. Twisk J, De Boer M, De Vente W, Heymans M (2013) Multiple imputation of missing values was not necessary before performing a longitudinal mixed-model analysis. J Clin Epidemiol 66:10221028. https://doi.org/10.1016/j.jclinepi.2013.03.017

68. Netten AP, Dekker FW, Rieffe C, Soede W, Briaire JJ, Frijns JHM (2017) Missing data in the field of Otorhinolaryngology and 
head and neck surgery: Need for improvement. Ear Hear 38:1-6. https://doi.org/10.1097/AUD.0000000000000346

69. Van Buuren S (2012) Flexible imputation of missing data. CRC Press, Boca Raton, FL

70. Schafer JL, Graham JW (2002) Missing data: Our view of the state of the art. Psychol Methods 7:147-177. https://doi.org/10.1037/ 1082-989X.7.2.147

71. Sterne JAC, White IR, Carlin JB, Spratt M, Royston P, Kenward MG, Wood AM, Carpenter JR (2009) Multiple imputation for missing data in epidemiological and clinical research: Potential and pitfalls. BMJ 339:157-160. https://doi.org/10.1136/bmj. b2393

72. Van gent T., Goedhart AW, Knoors HET, Westenberg PM, Treffers PDA (2012) Self-concept and ego development in deaf adolescents: A comparative study. J Deaf Stud Deaf Educ 17:333-351. https://doi.org/10.1093/deafed/ens002

73. Wolters N, Knoors HET, Cillessen AHN, Verhoeven L (2011) Predicting acceptance and popularity in early adolescence as a function of hearing status, gender, and educational setting. Res Dev Disabil 32:2553-2565. https://doi.org/10.1016/j.ridd.2011. 07.003
74. Ungar M (2017) Which counts more: differential impact of the environment or differential susceptibility of the individual? Br $\mathbf{J}$ Soc Work 47:1279-1289. https://doi.org/10.1093/bjsw/bcw109

75. Van der Straaten TF, Briaire JJ, Dirks E, Soede W, Rieffe C, Frijns JH (2021) The school career of children with hearing loss in different primary educational settings - A large longitudinal nationwide study. J Deaf Stud Deaf Educ 1-12. https://doi.org/10. 1093/deafed/enab008

76. Batten G, Oakes PM, Alexander T (2014) Factors associated with social interactions between deaf children and their hearing peers: a systematic literature review. J Deaf Stud Deaf Educ 19:285-302. https://doi.org/10.1093/deafed/ent052

77. Xie YH, Potměšil M, Peters B (2014) Children who are deaf or hard of hearing in inclusive educational settings: A literature review on interactions with peers. J Deaf Stud Deaf Educ 19:423437. https://doi.org/10.1093/deafed/enu017

78. Zaidman-Zait A, Dotan A (2017) Everyday stressors in deaf and hard of hearing adolescents: the role of coping and pragmatics. J Deaf Stud Deaf Educ 22:257-268. https://doi.org/10.1093/deafed/ enw103 